\title{
BMJ Open Mothers' perceptions of the UK physical activity and sedentary behaviour guidelines for the early years (Start Active, Stay Active): a qualitative study
}

\author{
Georgina F Bentley, ${ }^{1,2}$ Russell Jago, ${ }^{2}$ Katrina M Turner ${ }^{1}$
}

To cite: Bentley GF, Jago R, Turner KM. Mothers' perceptions of the UK physical activity and sedentary behaviour guidelines for the early years (Start Active, Stay Active): a qualitative study. BMJ Open 2015;5:e008383.

doi:10.1136/bmjopen-2015008383

- Prepublication history for this paper is available online. To view these files please visit the journal online (http://dx.doi.org/10.1136/ bmjopen-2015-008383).

Received 2 April 2015 Revised 28 July 2015 Accepted 30 July 2015

CrossMark

\footnotetext{
${ }^{1}$ Centre of Academic Primary Care, School of Social and Community Medicine, University of Bristol, Bristol, UK

${ }^{2}$ Centre for Exercise, Nutrition \& Health Sciences, School for Policy Studies, University of Bristol, Bristol, UK
}

\section{Correspondence to} Georgina Bentley; georgina.bentley@bristol.ac. uk

\section{ABSTRACT}

Objectives: Higher levels of physical activity (PA) during early childhood have been associated with improved health outcomes, whereas sedentary behaviour (SB) has been associated with poorer health outcomes in children. In 2011, the UK produced guidelines for PA and SB in children under 5 years. Mothers have been identified as key influences in young children's PA and SB. The aim of this study was to use in-depth interviews with mothers of preschool children to examine attitudes to the guidance.

Design: Qualitative study using one-to-one, semistructured interviews; Data were analysed thematically using a framework approach.

Setting: Mothers were recruited from preschools, nurseries, and mother and toddler groups located in four areas of varying socioeconomic status within Bristol, UK.

Participants: 24 mothers who were considered the main or joint carer for a preschool child who was at least 2 years of age but had not yet started formal schooling.

Results: Mothers are not aware of the UK PA and SB guidelines for the early years. They believe that their child achieves the guideline targets for PA and SB and therefore, they do not believe these quidelines are relevant to them. Mothers feel that an increase in PA and reduction in $\mathrm{SB}$ (especially screen-viewing) would cause stress for mothers. Mothers found defining and quantifying PA and SB in their preschool child problematic.

Conclusions: As mothers do not identify with the need to increase PA or reduce SB in their child, awareness of the guidelines alone is unlikely to initiate behaviour change. Information on how mothers can make a more accurate assessment of their preschool child's PA and SB levels, and information about the benefits of increased PA and reduced SB should be provided alongside the guideline targets. Clear messages need to be developed that reframe the guidelines into pragmatic and usable targets.

\section{BACKGROUND}

Higher levels of physical activity (PA) and lower levels of sedentary behaviour (SB)

\section{Strengths and limitations of this study}

- The results of this paper provide a useful insight into the impression the UK physical activity and sedentary behaviour guidelines for the early years makes on mothers. The findings are informative for the development and dissemination of physical activity and sedentary behaviour promotion initiatives for the early years, and the design of the interventions.

- A diverse sample of mothers were recruited in terms of varying socioeconomic status areas, which included both urban and rural areas, working and non-working mothers and lone parents.

- The majority of mothers were of white ethnicity and the views of other ethnic groups were not represented.

- Mothers may have been inclined to give socially desirable responses and there was a possibility of selection bias as it may be that mothers with an interest in physical activity were more willing to take part in the study.

during early childhood (under 5 years) have been associated with a number of improved health and developmental outcomes. ${ }^{1-16}$ In recent years, there has been growing research interest in the $\mathrm{PA}$ and $\mathrm{SB}$ levels of children under the age of 5 and a number of nations (Australia, ${ }^{17}$ Canada, ${ }^{18}{ }^{19}$ USA $^{20}$ and the $\mathrm{UK}^{21}$ ) have produced PA and SB guidelines for this age group. In the UK, the four Chief Medical Officers published PA and SB guidelines for the early-years (from birth to 5 years) for the first time in $2011 .^{21}$ The UK guidelines state that children under 5 years who can walk unaided should be physically active for at least $180 \mathrm{~min}$ each day. This PA can be of any intensity (low-to-vigorous intensity), and spread throughout the day. PA in this age group mostly comprises of active play, which the guidelines define as an 
activity that involves moving the trunk and more exertion than the minimal movement required to carry out everyday tasks, such as washing and dressing or passive play (eg, craft activities, dressing up or playing at a sand table). In addition to active play, active travel may also be an important contribution to young children's PA (eg, walking). The SB guidelines advise that for both children who can and cannot walk, extended periods of sedentary time should be minimised (except sleeping). SB in this age group includes being restrained in a car seat, highchair or pushchair, screen-viewing, crafts, reading and puzzles. The guidelines emphasise that time spent restrained in car seats, highchairs or pushchairs and screen-viewing are the targeted SBs to be reduced. Unlike other nations, ${ }^{17} 1920$ the UK guidelines do not provide an advised maximum time for screenviewing. ${ }^{21}$ The Australian ${ }^{17}$ and Canadian ${ }^{19}$ guidelines suggest that children between 2 and 5 years of age should have less than $1 \mathrm{~h}$ and the American ${ }^{20}$ guidelines suggest less than $2 \mathrm{~h}$ of screen-viewing time per day.

Although the UK guidelines refer to any intensity of PA, the majority of studies measuring PA levels in preschoolers (age 3 until start of formal schooling, usually at age 5) only report minutes of moderate-to-vigorous PA per day. ${ }^{22} 23$ Thus, based on the current data it is difficult to draw any meaningful conclusions about UK preschoolers' overall activity levels in relation to the UK guidelines. In addition, variations in study methodologies (sampling, accelerometer wear time) as well as accelerometer models and cutpoints used to process accelerometer data make it difficult to accurately compare data and draw conclusions on preschoolers' activity levels. ${ }^{24}{ }^{25}$ Despite these limitations, current accelerometer ${ }^{22} 23$ and parent-report ${ }^{26}$ derived data of preschoolers' PA levels indicate that they may not be meeting the UK government's recommendations. Research also suggests that screen-viewing accounts for a considerable amount of a preschool child's day, with many children exceeding $2 \mathrm{~h}$ per day. ${ }^{27}{ }^{28}$ This evidence highlights the need to identify ways to encourage PA and reduce screen-viewing among preschool children.

Parents play a key role in influencing preschoolers' PA and $\mathrm{SB},{ }^{27} 29-33$ and are likely to be key mediators of behaviour change. ${ }^{4} 34{ }^{35}$ It is, therefore, important to understand their views towards these behaviours and whether they view the UK guidelines as realistic and appropriate. The aim of this study was to examine mothers' attitudes to the UK PA and SB guidelines for the early years.

\section{METHODS}

In-depth interviews were held with mothers of preschool children (aged 2 years until they started formal schooling). We included 2-year-olds in our definition of preschool in order to align our study with the UK PA and SB guideline's that are divided into two groups of children who have not yet started formal schooling: children who can and cannot walk. By the age of 2 years, the majority of children are competent walkers. Only mothers were recruited for this study as they tend to be the main caregiver. GFB, who has experience in qualitative research and had completed qualitative research training, carried out the recruitment and data collection.

\section{Recruitment and sampling}

Recruitment was targeted within four areas of varying socioeconomic status (SES), and in rural and urban communities in order to see if there were differences in mothers' perceptions within these areas. SES was defined by tertiles of the 2010 index of multiple deprivation (IMD) (http://data.gov.uk/dataset/index-ofmultiple-deprivation), assessed by residential postcode. The IMD score estimates area deprivation based on indicators of income, health, education and employment status, where a higher score equals a higher level of deprivation. One urban neighbourhood from each of the first, second and third tertile of the IMD within the City of Bristol, UK and one rural neighbourhood $13 \mathrm{~km}$ south of Bristol (second tertile of IMD) were targeted for recruitment.

The managers of centres and groups that were within the four areas were contacted to gain permission for the researcher to speak directly to mothers attending their centre. Information about the study was given via posters and leaflets to preschools, day nurseries and mother and toddler groups located within these areas at least 1 week prior to recruitment. GFB approached mothers face-to-face either during the group time or at child pick-up/drop-off time. Mothers were provided with a study information sheet and asked if they would be willing to take part in a one-to-one interview. They were given time to read the information sheet and asked to return a signed consent form to the researcher, via a prepaid envelope, if they were willing to take part. Once the consent form had been received by the researcher, mothers were contacted via telephone to arrange the interview. Mothers were eligible to take part if they were the main or joint carer for a preschool child, and could speak English.

Fourteen centres were approached for recruitment. Of these, eight allowed face-to-face recruitment with mothers and a further three allowed information to be given to mothers via centre staff. Forty-two mothers verbally agreed to take part in the study (9 from high-SES, 12 from mid-SES, 8 from low-SES and 13 from a rural mid-SES area). Forty of these were approached via face-to-face recruitment, and two contacted the researcher after reading an information sheet. Interviews were arranged at a time and place that was convenient for the mother. Those who were unable or unwilling to meet face-to-face were offered the option of a telephone interview.

\section{Data collection}

Three mothers dropped out of the study when contacted to arrange an interview (1 high-SES, 2 rural), and a further four participants did not turn up for the 
interview (2 low-SES, 1 mid-SES, 1 rural). Most of the interviews were held between April and June 2013, and a further four were undertaken in May 2014. All were conducted by GFB. The last four interviews were held because initial analyses revealed that data saturation had not been met. The time delay in conducting these interviews was due to GFB being on maternity leave. A semistructured topic guide was used to ensure consistency across the interviews. Areas discussed in the interviews included:

1. Details of their family and their preschool child's personality

2. Details of the preschool child's week and daily routine (including opportunities for PA and $\mathrm{SB}$ )

3. Participants' views on their child's PA and SB behaviours

4. Participants' reactions to the UK PA and SB guidelines for the early years.

This paper focuses on parents' reactions to the UK PA and SB guidelines. The interviewer first asked participants if they knew of the UK PA and SB guidelines for preschool children. The interviewer gave a description of the main PA and SB targets set out by the guidelines (ie, $180 \mathrm{~min}$ $(3 \mathrm{~h})$ of PA per day and a reduction in sedentary time) and participants were asked to discuss their reactions to this. A further explanation was then given of the details of the PA and sedentary behaviour guidelines (ie, the range of intensity PA included in the guidelines, the definition of active play and activities considered sedentary), and participants were again asked to give their reaction to this and discuss them in relation to their preschool child.

Twenty-six interviews were carried out and lasted between 23 and $67 \mathrm{~min}$ (mean $46 \mathrm{~min}$ ). Two interviews were terminated (at the request of the participant because of childcare problems) before the guidelines were discussed and so were not included in this analyses. Ten interviews were conducted in the parents' home, three within the location of recruitment (children's centre), and 13 over the telephone. Data collection and analysis were undertaken in parallel, so that themes from earlier data collection could inform the focus of later interviews and enable GFB to establish when sufficient data had been collected. Data collection ended when data saturation had been reached, that is, no new themes emerged from the analysis.

\section{Data analysis}

Interviews were audio recorded, and subsequently transcribed verbatim by an external transcription company. GFB anonymised the transcripts before analyses started. Data were analysed using thematic analysis. ${ }^{36}$ This initially involved reading and re-reading the interview transcripts in order to gain an overall understanding of the mothers' views and experiences, and to consider what codes could be applied to the data. Two researchers (GFB and KMT) independently read and coded a sample of transcripts. Discrepancies in coding were then discussed. This led to new codes being developed and existing codes being deleted or defined more clearly. Once the data had been fully coded, data coded under specific codes were retrieved and overarching or central themes identified.

Our analytical approach enabled us to make comparisons within and across the transcripts, and was inductive in nature; this ensured our findings stayed grounded in the data. To avoid bias, we independently coded transcripts, looked for deviant cases, discussed our interpretation of the data within the research team and ensured all findings could be traced back to sections of the transcripts.

Transcripts were imported into NVivo (V.10.0, QSR, Southport, UK) to allow for electronic coding and retrieval of data. To assist with the systematic interpretation of the data, an approach based on framework analysis ${ }^{37}$ was used. This entailed summarising data pertaining to specific codes in tables. Comparisons were then made within and across the data. Quotes reproduced in this paper have been tagged with the interview number, whether the interviewee resided in the low-SES, mid-SES, high-SES or rural mid-SES location and the sex of the child.

\section{RESULTS}

Details of participants interviewed are provided in table 1. Mothers had an average of 2.2 children (ranging from 1 to

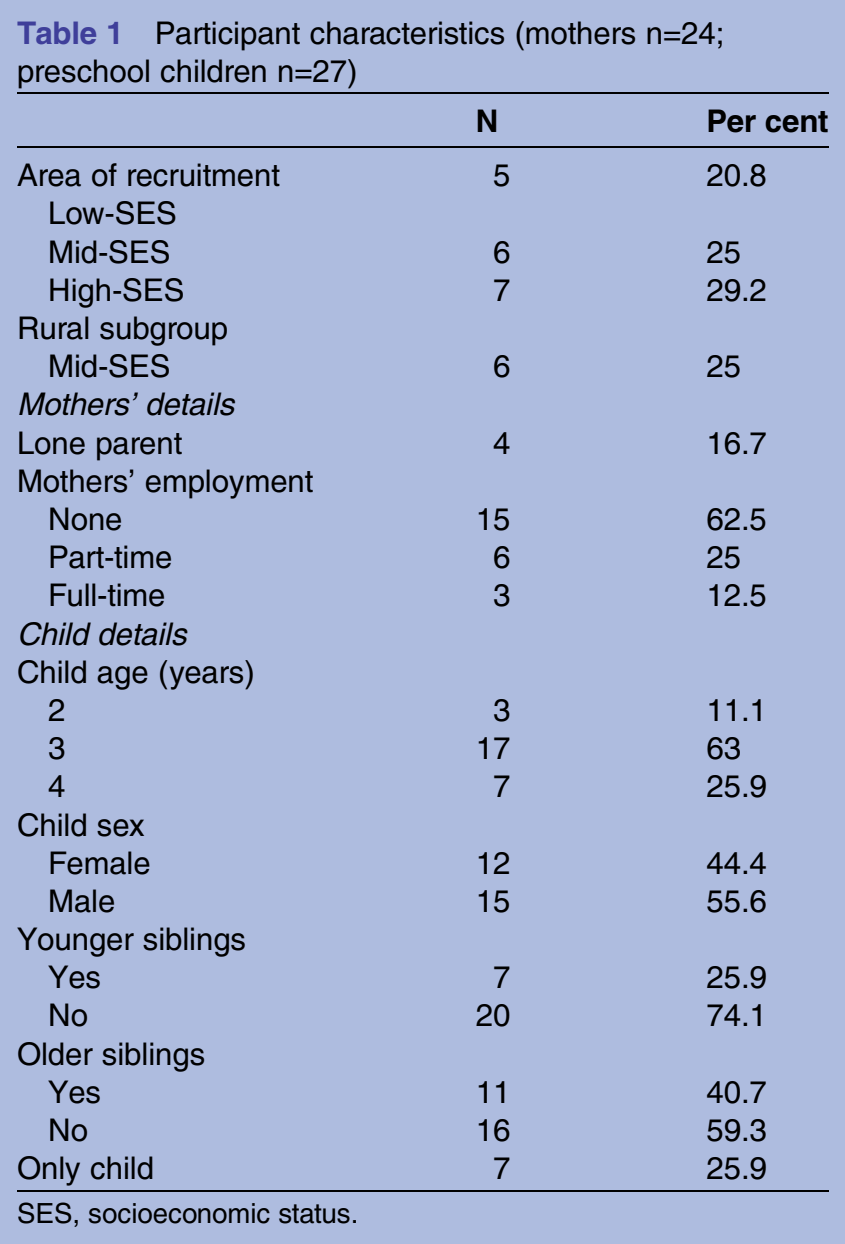


4 children), with an age range of 7 months to 14 years. Three of the mothers had two children of preschool age, in which case both children were discussed in the interview. Results are presented below under four main headings: (1) knowledge of the guidelines; (2) reactions to the PA targets; (3) reactions to the SB targets; (4) feelings towards the guidelines. Table 2 gives an overview of these results. Initial analyses showed that similar beliefs were expressed from mothers regardless of the area they resided in or the sex of their preschool child.

\section{Knowledge of the guidelines}

Around $90 \%$ of participants said they were not aware of the PA and SB guidelines for preschool children. A few were aware they existed but did not know what these were. Only one mother had read the guidelines (mid-SES). She had specifically sought out the information as she was keen to find out about obesity prevention strategies for her son.

Participant: Yes it's something that I've been aware of because I know I don't, I'm quite bonny [overweight] and my husband's quite overweight... so I think it's made me sort of hyper aware for [Son] and not wanting him to be in the same position that I am.

Interviewer: So it was actually something you actively looked into?

Participant: Yes, yes. P44, Mid SES, Boy

\section{Reactions to the physical activity targets}

Initially, most participants reported that they felt the target of 180 min per day sounded a lot to achieve. However, once it was explained that the $180 \mathrm{~min}$ could be spread throughout the day, could be of any intensity and a definition of PA was given, nearly all of the participants felt that the guidelines were easily achievable and some felt that their child exceeded this target. Just two mothers (both parents of girls and from the high-SES area) felt their child was not very active. They both said that this was because they felt that their child was predominantly interested in sedentary activities such as reading or crafts. All mothers from the low-SES, mid-SES and rural mid-SES area felt that their child was sufficiently active or very active.

It seems high but when you think about the amount of things that you do in a day then it is actually quite easy to reach that time. It does sound daunting, 3 hours is a long time. But when you break it down... P35, High SES, 2 boys

I think she's probably a bit below average in terms of energy, I don't think she's one of those hyper children definitely not because she's always been quite a calm child really in a way. I think really probably she's a quieter kind of child in terms of, she has the energy but she chooses not to, do you know what I mean she likes to sit and look at a book or something so challenging her mind rather than burning it all off running about I think. P14, High SES, Girl

Around two-thirds of mothers held the view that preschool children were naturally very active, they needed little encouragement to be active, and some felt that their child had no capacity for more activity. Mothers suggested that children need periods of rest because they get tired from their high-activity levels.

\begin{tabular}{|c|c|}
\hline \multirow{2}{*}{$\begin{array}{l}\text { 1. Knowledge of the PA and SB } \\
\text { guidelines }\end{array}$} & Most mothers were not aware of the guidelines \\
\hline & $\begin{array}{l}\text { A few mothers knew that they existed, but did not know the recommended PA or SB } \\
\text { targets }\end{array}$ \\
\hline \multirow[t]{3}{*}{ 2. Reactions to the PA targets } & Mothers felt that the targets were easily achievable and their child already met them \\
\hline & $\begin{array}{l}\text { Preschool children were seen as naturally active and mothers commented that there was } \\
\text { no more capacity from the parent or child to achieve more activity }\end{array}$ \\
\hline & $\begin{array}{l}\text { Mothers were uncertain how to define and quantify physical activity in their preschool } \\
\text { children }\end{array}$ \\
\hline \multirow[t]{6}{*}{ 3. Reactions to the SB targets } & Mothers felt that the SB guidelines were acceptable \\
\hline & $\begin{array}{l}\text { Most mothers felt that their preschool child had appropriate levels of SB and } \\
\text { screen-viewing }\end{array}$ \\
\hline & Many mothers had rules and restrictions on screen-viewing time \\
\hline & Screen-viewing was viewed as acceptable and beneficial in moderation \\
\hline & $\begin{array}{l}\text { There was some concern that activities that mothers valued, such as crafts and reading, } \\
\text { were included in the SB guidelines }\end{array}$ \\
\hline & $\begin{array}{l}\text { Reducing time spent in car seats and pushchairs was not seen to be feasible by some } \\
\text { mothers }\end{array}$ \\
\hline $\begin{array}{l}\text { 4. Attitudes towards the PA and } \\
\text { SB guidelines }\end{array}$ & $\begin{array}{l}\text { The guidelines were viewed as too broad and mothers suggested making them more } \\
\text { specific to make appropriate for developmental stages, gender, and natural activity levels } \\
\text { There was concern that the guidelines may cause stress and guilt for parents }\end{array}$ \\
\hline
\end{tabular}


I don't know how easy it would be though to increase it, we do quite a lot... he does normally just get quite tired near the end of the day so I would have thought he is already at his max. P28, Rural Mid-SES, Boy

The definition of PA in preschool children was questioned by around three-quarters of the mothers interviewed. They found it hard to classify children's activity and play as either physically active or sedentary, especially activities such as dressing up, crafts and play around the home. Television viewing (TV) was disputed as a sedentary activity because their child was often moving around or playing while the TV was on. Participants explained that their uncertainty in defining PA for preschool children, and the sporadic nature of their child's play made it very difficult to assess how much activity their child did in a day.

It depends on I guess what you say that it [PA] actually is. If it is just kind of playing. Yeah I think it's very difficult at that age to measure it... It does seem a lot though, but I would think, I have no idea how she compares to that P10, Low SES, Girl.

I think it's quite a random number to come out really because I think preschool children play in different ways really and erm you know like my daughter probably ends up walking quite a long way because she spends a lot of the day on her feet but she doesn't actually probably, I mean she does a little bit of running but she's not erm running all over the place the whole time, so yes I don't know it's a bit, I don't know I think it is a very difficult thing to calculate. P43, Mid SES, Girl

Mothers defined their child's PA using a number of different examples (not all of which would be classed as physically active according to the guidelines). These included types of play (eg, playing with siblings, outdoor play, role play, imaginative play), organised activities and groups (eg, rugby, swimming, toddler groups), being in formal day care (eg, nursery or preschool), active transport (walking to and from school, not using the pushchair) and the nature of their personality (eg, being on the go all the time, not sitting down, taking an active interest in things and asking questions).

He definitely will have had over 3 hours because he's been in the garden in the morning and the afternoon he's been at preschool. P35, High SES, Boy

\section{Reactions to the sedentary behaviour targets}

Most participants considered the guideline's suggestion that sedentary time should be reduced to be acceptable and sensible. One mother remarked that the aim of reducing $\mathrm{SB}$, rather than setting a specific time limit, made it more achievable.

Yes I suppose that's good isn't it because that's immediately achievable by everybody because to reduce it means it doesn't matter whether it's a reduction of 5 minutes or
3 hours if you're reducing it you're actively thinking about trying to get them to put the games console down or do something different. P14, High SES, Girl

Preschool children's SB was often described as a period of time to relax, unwind or calm down by mothers. Mothers most commonly referred to screenviewing when talking about this time, but also mentioned other activities such as cuddles, reading, napping, having milk and snacks, cooking and crafts. Time spent in a car seat or pushchair was not mentioned as a SB unless prompted by the interviewer.

Um she loves cooking, so we tend to do a bit of cooking usually in the morning, they like that, and then quite often, we'll just cuddle up on the sofa and watch a film or things like that. P18, Mid SES, Girl

Most of the mothers interviewed felt that minimising screen-viewing was sensible and feasible, and some acknowledged adverse effects of screen-viewing for their child. These adverse effects included that screen-viewing is addictive, distracts the child from playing, and makes their child unresponsive. However, many parents were unable to define why they thought that screen-viewing should be minimised.

I just don't like them to watch too much TV, I don't like the thought that they're just sat there. P13, Mid SES, Boy

Although the majority of mothers felt that minimising screen-viewing was appropriate, they also felt that their child currently had acceptable levels of screen-viewing and no reduction was necessary. Mothers who expressed concerns over the effect of screen-viewing on their child talked about actively monitoring its use using strategies such as breaking up TV watching time during the day and setting time limits. However, parents admitted it was easy to lose track of how much time their child spent screen-viewing.

Sometimes I do feel like she's been on the tablet for too long as well erm because sometimes before you realise she's been sort of playing games and watching songs and things for like you know half an hour and then it's an hour and you didn't realise, because you've been busy doing stuff you realise she's just been sat there doing it. P12, High SES, Girl

The majority of mothers also felt that screen-viewing in moderation was acceptable as long as it was balanced alongside PA and other activities. Screen-viewing was often seen to be a useful educational tool and a way for preschoolers to rest.

Um I think everything in moderation really. There are days if they're under the weather, or they're tired, they're quite happy to sit down all day and I don't think that's a bad thing, but I think, as long as they get some exercise most days. P15, Mid SES, Girl 
I would agree in terms of I think less telly would be a good thing... but if they're ... or if, you know, if they're watching some of the programmes which are clearly like about developing language or letters or numbers, educational. I think you need to define sedentary activity better. P31, High SES, 2 Boys

There was some concern that sedentary activities may be included in the guidelines that mothers valued for their child, especially crafts and reading. Many mothers felt that a balance of activities is appropriate and rest, crafts and intellectual activities were as important as PA.

Yeah fair enough, they shouldn't be doing that [spending a long time screen-viewing] but generally no, every child I think no matter what their age, even the parents like that, nice quiet time, having cuddles, reading a story together you know. P22, Low SES, Boy

I don't know, I think if they're probably doing 3 hours ... because there's benefits to that as well so ... there's benefits to sitting down doing something ... you know, they can ... I don't know, be creative and use their imagination I think that's important as well. P21, High SES, 2 Girls

The practicalities of reducing time spent in a pushchair or car seat were questioned by some mothers. Mothers felt that they were only used when really necessary and it was suggested that this was not an appropriate expectation of the guidelines.

I think the pushchair or car seat thing erm isn't always an achievable thing to... not all pre-school children like to walk the way that you want to walk. And so actually it's not, you know it could be along a busy road you know or they could just want to be looking at everything else and you actually need to get from A to B so it's not always a possible thing to achieve things like that. P43, Mid SES, Girl

\section{Attitudes towards the guidelines}

Some mothers reported that they felt the guidelines were unnecessary. For example, two parents mentioned that if they had heard of the guidelines they would not have taken notice of them because they felt their child was sufficiently active. In addition, another parent felt they were not relevant to her family.

I'd like to think that we were on the healthier side of the middle start. I kind of look at the, not that, you know, I'm feeling smug and saying well it doesn't affect me but more that we're consciously doing it already. But I think the Government recommendations are really to try and pull those people who, you know, chuck the kids in front of the TV all day long... and you know sort of give them crisps and chocolate all day long. P36, High SES, 2 Girls

One mother suggested that preschool children did not need additional encouragement to be active as they are already sufficiently active.
I think most children are generally active at that age. I don't, they don't need the encouragement that adults need. P15, Mid SES, Girl

The guidelines were viewed as being too broad, and some mothers gave suggestions on how this may be improved. For instance: making the guidelines gender specific to accommodate the different playing styles of boys and girls (boys being described as engaging in boisterous play, and girls engaging in creative and imaginative play); making the guidelines age specific to allow these to be more appropriate for the developmental stages of this age group (a 2-year-old plays very differently to a 5-year-old); and making them adaptable for children with different activity levels so that children with low levels of activity may receive different recommendations than children with high levels of activity.

Erm, reduced from what, though because I think that's different for different personalities, because you've got some children, especially boys, you cannot get them to sit down and colour a picture because they're just not interested but girls will quite happily kneel down and play with a dolls house for hours....I think I know it really is a blanket statement but I think in general boys and girls are different like that because of the you know the fine motor skills for girls and then the large motor skills for boys. P39, Low SES, Boy

Um I'd say at a five year old level then yes, but under five, I mean is that literally from walking to five is it? Yeah I'd say it's a bit unachievable for kind of a two year old. P15, Mid SES, Girl

Participants were concerned the guidelines could cause some stress and pressure for parents. Increasing PA was thought to require extra effort from the mother, which often did not feel feasible due to their own energy and time constraints. This was felt to cause a feeling of failure or guilt for some mothers who did not feel they had the capacity they felt was required to provide their child with additional activity opportunities.

Um, I don't think I'd be able to cope with 3 hours of activity every day to be honest you know. I'm a busy mum, I've got a lot to do. Housework and everything else you know. It's impossible for me to be able to just kind of put that amount of time aside to do something. P22, Low SES, Boy

Ideally all parents would like to do this, it's good to have the reminder but the reality isn't that easy. If a mum has had a bad day or the child is having a bad day then you'd take them out in the car or sit them in front of the TV just to get through it. It helps. It puts a lot of pressure on parents. If someone asked me to reduced sedentary time I would be mindful of it but I would be shocked that they asked. P57, Rural Mid-SES, Boy

Some mothers gave suggestions on how parents may help their child achieve the guidelines. When giving 
these suggestions they were talking about 'other mothers' and not in relation to their own circumstances because they did not feel that their families needed change. These included lifestyle changes such as walking rather than using a pushchair or the car, providing more opportunities to play outdoors, enrolling the child in organised activities, being more involved and playing with the child, and encouraging creative activities as a replacement to screen-viewing.

\section{DISCUSSION}

The data presented in this paper suggests that mothers of preschool children are not aware of the $\mathrm{PA}$ and $\mathrm{SB}$ targets in the UK guidelines for the early years. Once informed about the guidelines, mothers felt that they were appropriate for preschool children in general but not relevant to their family, mainly because they believed that their preschool child was already meeting the guideline PA and SB targets. This was reflected in the tendency for mothers to talk about 'other families' when discussing the guidelines as they felt that their own family had no need for change or that the guidelines were aimed at 'other families'. This inclination to deflect discussion of screen-viewing in their child to other parents because they do not see a relevance for their family has been noted by another qualitative study. ${ }^{38}$

Mothers in this study were unaware of the specific PA and SB targets for the early years. The guidelines state that the aim is for as many people as possible to use them and achieve the guidelines recommended activity levels. ${ }^{21}$ However, following the development of the guidelines in 2011, there was no specific health campaign to publicise the new PA and SB targets; however, these were incorporated into the pre-existing Change4Life social marketing campaign and National Health Service Choices promotional material. ${ }^{39}$ No other studies have investigated parental knowledge of child PA guidelines, but a national survey conducted 2 years following the publication of the guidelines found that only $18 \%$ of adults could correctly recall the current PA guidelines. ${ }^{40}$ This lack of awareness of the guidelines is evident in this sample of mothers' and reflects the ineffectual dissemination of the new advised PA and SB targets. This is not a problem unique to the UK as mothers from Canada have also been reported have a lack of knowledge of their SB guidelines. ${ }^{41}$ Mothers interviewed in the Canadian study suggested that guideline information was provided through healthcare professionals early on during motherhood or even during pregnancy to prevent sedentary habits from forming. ${ }^{41}$

Knowledge of the PA guidelines has been shown to be important to instigate behaviour change. ${ }^{42}$ However, results from this study indicate that mothers may not be receptive to the guidelines because they feel, for example, their preschool child is already engaging in sufficient PA and therefore, do not feel the guidelines are relevant to them. This suggests that presenting mothers with PA and SB targets alone is not sufficient to instigate behaviour change and that further actions are needed. In addition to this, mothers were concerned that an increase in PA may be problematic for them or their child as they felt they were doing as much as they were able to do. This study and others indicate that some parents have concerns that increased PA and reduced SB means the displacement of activities mothers' value such as reading and crafts. ${ }^{38} 4143$ In addition to this, mothers reported that they were satisfied with the amount of time their child spent screen-viewing and they had no need or desire to make any changes. Screen-viewing was valued as an educational tool as well as a means for preschoolers to relax. However, a systematic review of sedentary behaviour and health indicators in the early years found that no evidence exists to indicate that TV-viewing is beneficial for cognitive development or psychosocial health. ${ }^{11}$ It has previously been reported that parents' use screen-viewing as a coping strategy, in order for them to either do household chores or rest themselves, ${ }^{38} 41{ }^{43}$ and this was also reported by mothers in this study. Children with parents experiencing high levels of parenting stress have been reported to be less likely to set limits on the amount of TV they watched by their parents (OR=0.32, 95\% CI 0.11 to 0.93 ) than children with normally stressed parents, ${ }^{44}$ thus highlighting the use of screen-viewing as a coping strategy for mothers. Some mothers reported that they enforced screen-viewing rules and restrictions, which have been cited to influence the type of sedentary activity a child participates in at home $;^{45}$ however, these restrictions were not always successful for these mothers. Therefore, when promoting the PA and SB guidelines to mothers, helping them identify a need for change and addressing barriers to change will need to be considered. Including specific strategies to support change to meet the guidelines would be welcomed by parents. ${ }^{41}$ Messages that are framed based on the potential gain to both the child and the parent (rather than negative or loss-framed messages), and that enhance self-efficacy have been cited as being most effective in PA promotion. ${ }^{46}$

The lack of translation of the guidelines into a message that is accessible and practical for public use is evident in this study, where many mothers found the terms 'physical activity' and 'sedentary behaviour' for this age group confusing and hard to define. Similarly, an Australian qualitative study by Dwyer et $a t^{47}$ found that parents considered the concept of PA intensity difficult to apply to their preschool child's PA. Mothers tend to describe their child as active, regardless of their true activity levels (ie, describing their child as active when they do not meet the government guidelines for PA), indicating that they may not be making accurate estimations. ${ }^{48}$ Identifying PA in this age group is challenging. First, the guidelines define PA as activities which involve movements of all the major muscle groups; however, activities such as dressing-up and playing at a sand table are also given as examples of non-physical activities, 
which some mothers in this study used as activities to describe their child's PA. This ambiguity and lack of clear distinction makes it difficult for parents to assess their own child's PA. Second, PA in preschoolers occurs in short spontaneous bouts throughout the day, thereby making calculating PA time problematic. In a recent accelerometry study, Ruiz et at $t^{49}$ identified four patterns to describe PA in preschool children where each contain varying brief periods of vigorous-PA, moderate-PA and light-PA, and sedentary activity throughout the day. Ruiz's study highlights that unlike adults and older children, preschool children incorporate PA in short bouts throughout most of their waking hours. Although the majority of mothers said that their preschool child was meeting the guideline targets, their uncertainty in defining and quantifying $\mathrm{PA}$ and $\mathrm{SB}$ of their child means they may not be making accurate assessments. Therefore, PA and SB recommendations need to be translated into accessible public messages that help mothers make more accurate estimations of their child's PA and SB levels. These messages should be clearly communicated and be appropriate to the child's developmental stage.

The data presented in this paper highlights similar views from mothers from varying SES, and urban and rural areas. A review of correlates of preschool children's PA reported that SES was not associated with PA. ${ }^{50}$ In addition, although some studies suggest that children from low-SES areas are more likely to have higher levels of screen-viewing, ${ }^{51}{ }^{52}$ a number of studies have suggest that screen-viewing time is equally distributed across SES groups. ${ }^{53-55}$ This finding might suggest that targeted health promotion efforts for preschoolers may not be required. Some mothers identified a need for genderspecific guidelines because of the different way in which boys and girls play. Correlates of preschool PA levels ${ }^{56}$ and compliance with screen-viewing recommendations ${ }^{53}$ varies between boys and girls. In addition, mothers felt that more specific guidance was necessary to account for differences in energy levels and age stages between children. This suggests that messages that mothers can identify with for children with different play styles, personalities and developmental stages should be considered.

\section{Strengths and limitations}

The results of this paper provide a novel and useful insight into the mothers' knowledge and perspectives of the guidelines; they are a fundamental influence on the PA and SB behaviours of preschool children. A strength of this study is that a diverse sample of mothers were recruited in terms of varying SES areas, which included both urban and rural areas, working and non-working mothers and lone parents. A sufficient number of mothers were interviewed from each area to reach data saturation. Interviews were carried out either face-to-face or over the telephone at any time that suited the parent, which provided flexibility to enable working and nonworking mothers to participate. A limitation of this study is that the majority of mothers were of white ethnicity and the views of other ethnic groups were not represented. Also, mothers may have been inclined to give socially desirable responses and there was a possibility of selection bias as it may be that mothers with an interest in PA were more willing to take part in the study.

\section{CONCLUSIONS}

The data presented here suggests that mothers are not aware that PA and SB targets for the early years are set by the UK government. Awareness of these guidelines is important if mothers are to help their child meet the targets. However, as mothers do not identify with the need to increase PA or reduce SB in their child, guidelines alone are unlikely to initiate behaviour change. Providing mothers with information on how they can make a more accurate assessment of their preschool child's PA and SB levels, and information about the benefits of increased PA and reduced SB would need to go hand-in-hand with improved dissemination of the guidelines in order for them to be meaningful to mothers. Clear messages need to be developed that reframe the guidelines into pragmatic and usable targets that families can relate to and feel able to achieve.

Contributors GFB conducted the study and drafted the paper. KMT assisted with the thematic analysis. KMT and RJ were involved in the design of the study and contributed to the drafting of the paper. All authors read and approved the final manuscript.

Funding This study was funded by a studentship awarded to GFB by Centre for Academic Primary Care at the University of Bristol (GR4036).

Competing interests None declared.

Ethics approval University of Bristol, Faculty of Medicine and Dentistry ethics committee.

Provenance and peer review Not commissioned; externally peer reviewed.

Data sharing statement No additional data are available.

Open Access This is an Open Access article distributed in accordance with the Creative Commons Attribution Non Commercial (CC BY-NC 4.0) license, which permits others to distribute, remix, adapt, build upon this work noncommercially, and license their derivative works on different terms, provided the original work is properly cited and the use is non-commercial. See: http:// creativecommons.org/licenses/by-nc/4.0/

\section{REFERENCES}

1. Timmons BW, Leblanc AG, Carson V, et al. Systematic review of physical activity and health in the early years (aged 0-4 years). Appl Physiol Nutr Metab 2012;37:773-92.

2. Timmons BW, Naylor PJ, Pfeiffer KA. Physical activity for preschool children-how much and how? Can J Public Health 2007;98: S122-34.

3. Collings PJ, Brage S, Ridgway CL, et al. Physical activity intensity, sedentary time, and body composition in preschoolers. Am J Clin Nutr 2013;97:1020-8.

4. Hinkley T, Teychenne M, Downing KL, et al. Early childhood physical activity, sedentary behaviors and psychosocial well-being: a systematic review. Prev Med 2014;62:182-92.

5. Tremblay MS, Leblanc AG, Kho ME, et al. Systematic review of sedentary behaviour and health indicators in school-aged children and youth. Int J Behav Nutr Phys Act 2011;8:98.

6. Saunders TJ, Chaput JP, Tremblay MS. Sedentary behaviour as an emerging risk factor for cardiometabolic diseases in children and youth. Can J Diabetes 2014;38:53-61. 
7. Prentice-Dunn H, Prentice-Dunn S. Physical activity, sedentary behavior, and childhood obesity: a review of cross-sectional studies. Psychol Health Med 2012;17:255-73.

8. Carson V, Janssen I. Volume, patterns, and types of sedentary behavior and cardio-metabolic health in children and adolescents: a cross-sectional study. BMC Public Health 2011;11:274

9. Stamatakis E, Coombs N, Jago R, et al. Type-specific screen time associations with cardiovascular risk markers in children. Am J Prev Med 2013:44:481-8.

10. Ekelund U, Brage S, Froberg $\mathrm{K}$, et al. TV viewing and physical activity are independently associated with metabolic risk in children: the European Youth Heart Study. PLoS Med 2006;3:e488.

11. Leblanc AG, Spence JC, Carson V, et al. Systematic review of sedentary behaviour and health indicators in the early years (aged 0-4 years). Appl Physiol Nutr Metab 2012;37:753-72.

12. Jago R, Baranowski T, Baranowski JC, et al. BMl from 3-6 years of age is predicted by TV viewing and physical activity, not diet. Int $J$ Obes 2005;29:557-64.

13. Hinkley T, Verbestel V, Ahrens W, et al. Early childhood electronic media use as a predictor of poorer well-being: a prospective cohort study. JAMA Pediatr 2014;168:485-92.

14. Manganello JA, Taylor CA. Television exposure as a risk factor for aggressive behavior among 3-year-old children. Arch Pediatr Adolesc Med 2009;163:1037-45.

15. Marinelli M, Sunyer J, Alvarez-Pedrerol M, et al. Hours of television viewing and sleep duration in children: a multicenter birth cohort study. JAMA Pediatr 2014;168:458-64.

16. Garrison MM, Liekweg K, Christakis DA. Media use and child sleep: the impact of content, timing, and environment. Pediatrics 2011;128:29-35.

17. Australian Government, D.o.H. Move and play every day. National physical activity recommendations for children 0-5 years. (2014 15 January 2015). http://www.health.gov.au/internet/main/publishing. nsf/content/health-pubhlth-strateg-phys-act-quidelines\#npa05

18. Tremblay M, Leblanc AG, Carson V, et al. Canadian physical activity guidelines for the early years (aged 0-4years). Appl Physiol Nutr Metab 2012;37:345-69.

19. Tremblay MS, Leblanc AG, Carson V, et al. Canadian sedentary behaviour guidelines for the early years (aged 0-4 years). Appl Physiol Nutr Metab 2012;37:370-91.

20. Education, N.A.f.S.a.P., Active Start. $A$ statement of physical acitvity guidelines for children from birth to age 5. 2nd edn. American Alliance for Health, Physical Education, Recreation, and Dance, 2009.

21. Department of Health, Start Active, Stay Active. A report on physical activity from the four home countries' chief medical officers. London: Department of Health, 2011

22. Tucker $P$. The physical activity levels of preschool-aged children: a systematic review. Early Child Res Q 2008;23:547-58.

23. Bornstein DB, Beets MW, Byun W, et al. Accelerometer-derived physical activity levels of preschoolers: a meta-analysis. J Sci Med Sport 2011;14:504-11.

24. Vale S, Santos R, Silva P, et al. Preschool children physical activity measurement: importance of epoch length choice. Pediatr Exerc Sci 2009;21:413-20.

25. Pate RR, O'neill JR, Mitchell J. Measurement of physical activity in preschool children. Med Sci Sports Exerc 2010;42:508-12.

26. Townsend N, Wickramasinghe K, Williams J, et al. Physical activity statistics 2015. London: British Heart Foundation, 2015.

27. Jago R, Edwards MJ, Urbanski CR, et al. General and specific approaches to media parenting: a systematic review of current measures, associations with screen-viewing, and measurement implications. Child Obes 2013;9(Suppl):S51-72.

28. Health Survey for England 2008. Physical activity and fitness. Leeds: The Information Centre, 2010.

29. Jago R, Sebire SJ, Wood L, et al. Associations between objectively assessed child and parental physical activity: a cross-sectional study of families with 5-6 year old children. BMC Public Health 2014;14:655.

30. Jago R, Sebire SJ, Edwards MJ, et al. Parental TV viewing, parental self-efficacy, media equipment and TV viewing among preschool children. Eur J Pediatr 2013;172:1543-5.

31. Jago R, Thompson JL, Sebire SJ, et al. Cross-sectional associations between the screen-time of parents and young children: differences by parent and child gender and day of the week. Int $J$ Behav Nutr Phys Act 2014;11:54.
32. Jago R, Wood L, Zahra J, et al. Parental control, nurturance, self-efficacy, and screen viewing among 5- to 6-year-old children: a cross-sectional mediation analysis to inform potential behavior change strategies. Child Obes 2015;11:139-47.

33. Oliver M, Schofield GM, Schluter PJ. Parent influences on preschoolers' objectively assessed physical activity. J Sci Med Sport 2010;13:403-9.

34. Vaughn AE, Hales D, Ward DS. Measuring the physical activity practices used by parents of preschool children. Med Sci Sports Exerc 2013;45:2369-77.

35. Loprinzi PD, Trost SG. Parental influences on physical activity behavior in preschool children. Prev Med 2010;50:129-33.

36. Braun V, Clarke V. Using thematic analysis in psychology. Qual Res Psychology 2006;3:77-101

37. Ritchie Jane SL. Qualitative data analysis for applied policy research. The qualitative researcher's companion. SAGE Publications, Inc. Thousand Oaks, CA: SAGE Publications, Inc., 2002:305-330.

38. He M, Irwin JD, Sangster Bouck LM, et al. Screen-viewing behaviors among preschoolers: parents' perceptions. Am J Prev Med 2005;29:120-5.

39. Milton K, Bauman A. A critical analysis of the cycles of physical activity policy in England. Int J Behav Nutr Phys Act 2015;12:8.

40. Knox EC, Esliger DW, Biddle SJ, et al. Lack of knowledge of physical activity guidelines: can physical activity promotion campaigns do better? BMJ Open 2013;3:e003633.

41. Carson V, Clark M, Berry T, et al. A qualitative examination of the perceptions of parents on the Canadian Sedentary Behaviour Guidelines for the early years. Int J Behav Nutr Phys Act 2014;11:65.

42. Snyder LB. Health communication campaigns and their impact on behavior. J Nutr Educ Behav 2007;39(2 Suppl):S32-40.

43. Hesketh K, Hinkley T, Campbell K. Children's physical activity and screen time: qualitative comparison of views of parents of infants and preschool children. Int J Behav Nutr Phys Act 2012;9:152.

44. Walton K, Simpson J, Darlington G, et al. Parenting stress: a cross-sectional analysis of associations with childhood obesity, physical activity, and TV viewing. BMC Pediatr 2014;14:244.

45. Knowles AM, Kirk AF, Hughes AR. Parents' perceptions of their children's sedentary behaviour. Qualitative Research in Sport, Exercise and Health, 2015:1-17.

46. Latimer A, Brawley L, Bassett R. A systematic review of three approaches for constructing physical activity messages: what messages work and what improvements are needed? Int J Behav Nutr Phys Act 2010;7:36.

47. Dwyer GM, Higgs J, Hardy LL, et al. What do parents and preschool staff tell us about young children's physical activity: a qualitative study. Int J Behav Nutr Phys Act 2008;5:1479-5868.

48. Kesten JM, Jago R, Sebire SJ, et al. Understanding the accuracy of parental perceptions of child physical activity: a mixed methods analysis. J Phys Act Health 2015. doi:10.1123/jpah.2014-0442

49. Ruiz RM, Tracy D, Sommer EC, et al. A novel approach to characterize physical activity patterns in preschool-aged children. Obesity 2013;21:2197-203.

50. Hinkley T, Crawford D, Salmon J, et al. Preschool children and physical activity: a review of correlates. Am J Prev Med 2008;34:435-41.

51. Lapierre MA, Piotrowski JT, Linebarger DL. Background television in the homes of US children. Pediatrics 2012;130:839-46.

52. Wijtzes Al, Jansen W, Kamphuis CBM, et al. Increased risk of exceeding entertainment-media guidelines in preschool children from low socioeconomic background: the Generation R Study. Prev Med 2012;55:325-9.

53. Hinkley T, Salmon J, Okely AD, et al. The correlates of preschoolers' compliance with screen recommendations exist across multiple domains. Prev Med 2013;57:212-19.

54. Vandewater EA, shim MS, Caplovitz AG. Linking obesity and activity level with childrens television and video game use. $J$ Adolesc 2004:27:71-85.

55. Kourlaba G, Kondaki K, Liarigkovinos T, et al. Factors associated with television viewing time in toddlers and preschoolers in Greece: the GENESIS study. J Public Health 2009;31:222-30.

56. Hinkley T, Salmon J, Okely AD, et al. Correlates of preschool children's physical activity. Am J Prev Med 2012;43:159-67. 